\title{
Electrochemical migration investigations on Sn-Sb solder alloys using 3.5 wt \% NaCl solution
}

\author{
Bálint Medgyes ${ }^{1)}$, Róbert Kiss $^{1)}$, Szabolcs Szurdán ${ }^{2)}$, Dániel Rigler ${ }^{1)}$, László Gá1 ${ }^{1)}$, Richárd Berényi ${ }^{1)}$ \\ and Gábor Harsányi ${ }^{1)}$ \\ ${ }^{1)}$ Department of Electronics Technology, Budapest University of Technology and Economics, Budapest, Hungary \\ ${ }^{2)}$ University of Miskolc, Faculty of Materials Science and Engineering, Miskolc, Hungary \\ medgyes@ett.bme.hu
}

\begin{abstract}
ECM (electrochemical migration) is sort of short failure mechanism, that can lead to series defect in case of loaded circuits, when moisture exist on/in a conductor-dielectric-conductor system. Water drop (WD) test and scanning electron microscopy - energy disperse spectroscopy (SEM-EDS) methods were used to investigate the ECM behavior on different Sn-Sb alloys and pure Sn was the reference. The results show that all of the samples have similar ECM risk comparing to the pure Sn. However, in case of Sn95-Sb5 solder alloy antimony was found in the dendrites next to Sn content, which was dominated during the ECM processes in all cases.
\end{abstract}

\section{INTRODUCTION}

Nowadays, several reliability topics of electronics have to be answered [1-4]. Electrochemical migration (ECM) failure phenomenon is one of the most dangerous ones. ECM may pose an extremely huge reliability problem related to electronics [5]. The ECM failure mechanism appears by a moisture appearance in the case of loaded electronics: the electrochemical oxidation of conductors beginning at the anode side and results in metal ions that are governed by the bias voltage and migrate towards the oppositely biased side, where they can form conductive filaments (reduction), called dendrites (Fig. 1). Dendrite formation can cause short. Several kind of the metals, that are widely applied in the electronics industry, have relevant susceptibility for ECM, such as tin, silver or copper [6]. ECM tests of Sn and Sn-alloys are widely reported as well [6-11]. There are three main ways to carry out ECM research [12]; WD test [13], climatic investigations under elevated relative humidity conditions [14] and by many electrochemical methods, such as voltammetry or polarization tests [15]. Furthermore, the electrochemical corrosion (ECC) and ECM research activities of Sn-alloys were usually carried out in bulk solutions. On the other hand, ECM researches in thin electrolyte layers (TEL) are also extremely important, hence ECM susceptibility depends on the water layer thickness as well [16]. Furthermore, the concentrations of the used wet environment have a wide spectrum as well: high purity water [6], acidic or alkaline electrolytes [8, 17] and also salts [18]. The most common contaminant type of salts is the $\mathrm{NaCl}$, that can have an extremely impact on the ECC failure processes and thus, the ECM susceptibility of tin and tin-based solder alloys as well. According our previous research work [19], it was firstly shown that next to the common used component of the solder alloy ( $\mathrm{Sn}, \mathrm{Ag}, \mathrm{Cu}$ ), antimony can also take part in the ECM processes using leadfree micro-alloyed solder alloy in $\mathrm{NaCl}$ environment. In this work we have produced different $\mathrm{Sn}-\mathrm{Sb}$ alloys to check the migration ability of antimony in $\mathrm{NaCl}$ environment. 


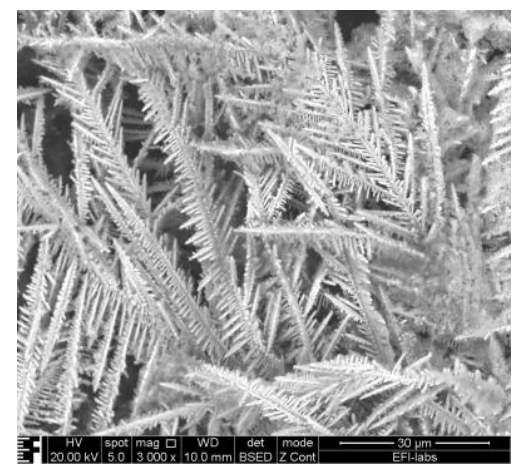

Fig. 1. SEM picture from Sn dendrites.

\section{EXPERIMENTAL}

\subsection{Sample preparation}

The following metal and alloys were prepared and investigated:

- Pure Sn,

- Sn99.9Sb0.1 wt\%,

- Sn99Sb1 wt\%,

- $\mathrm{Sn} 97 \mathrm{Sb} 3 \mathrm{wt} \%$,

- Sn95Sb5 wt\%.

The pure Sn sample was prepared according to the conventional PCB technology using electroplating and chemical etching techniques. For the solder alloy samples immersion silver (iAg) was used as a surface finish with the same dimension of the pure Sn sample (See Fig 2.).

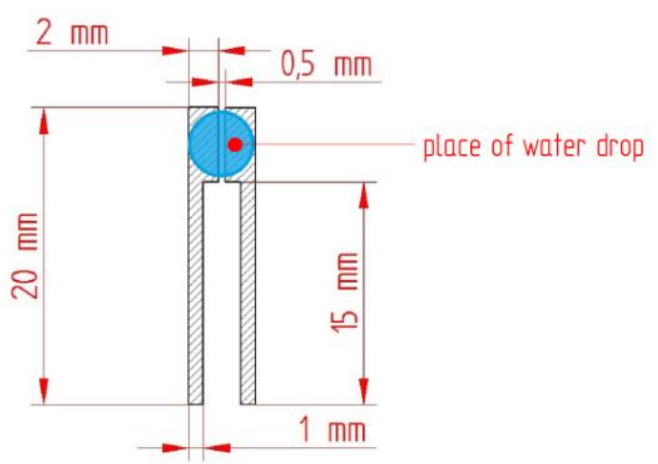

Fig. 2. Dimension of the test structure for WD test.

The preparation of the $\mathrm{Sn}-\mathrm{Sb}$ solder alloy samples contained many steps. Firstly, we have received solder alloy ingots from a Metal Foundry (See Fig 3).

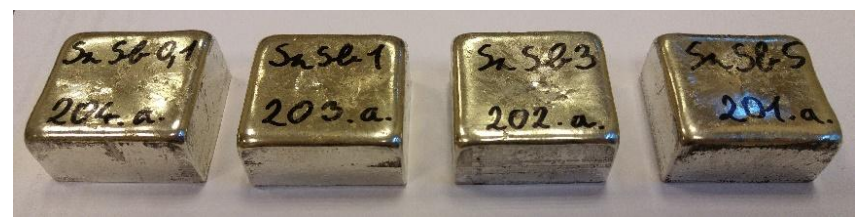

Fig. 3. Sn-Sn solder alloy ingots. 
In the next step the ingots were rolled to flat layer with $0.5 \mathrm{~mm}$ thickness (Fig. 4). Afterwards a special tool was design and prepared (Fig. 5.) to rich adeguate preforms in a phisical way (Fig. 6) for the test board. Finally, the preforms were melted on the layout using hand soldering methods (Fig 7.). After the soldering the samples were cleaned by iso-propil-alcohol and rinsed with deionised water (Fig. 8).

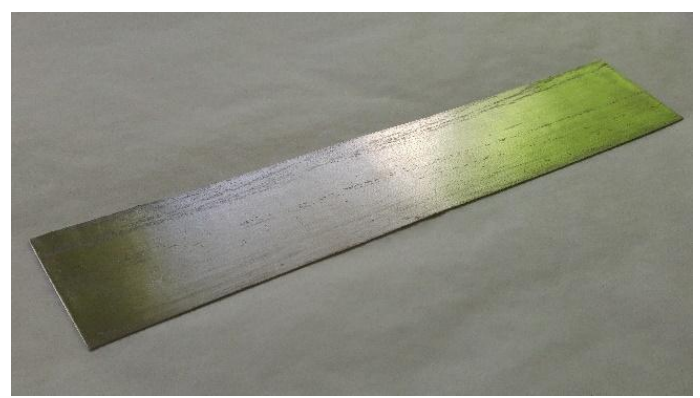

Fig. 4. Sn-Sn solder alloy plate after rolling.

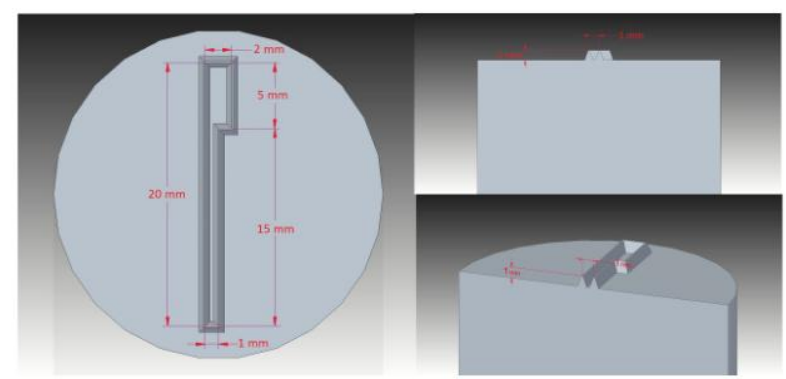

Fig. 5. Design of the cutting tool for preform preparation.

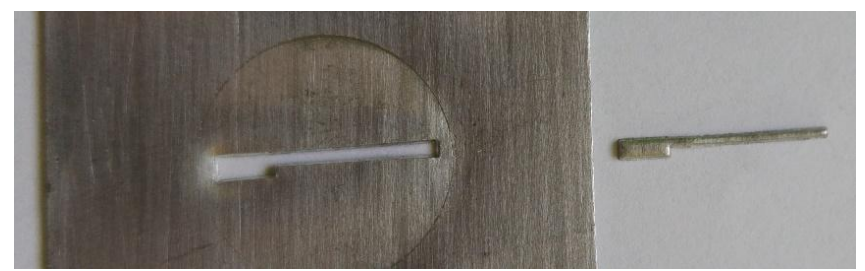

Fig. 6. Preform (right) after using the cutting tool on the rolled solder alloy plate (left).

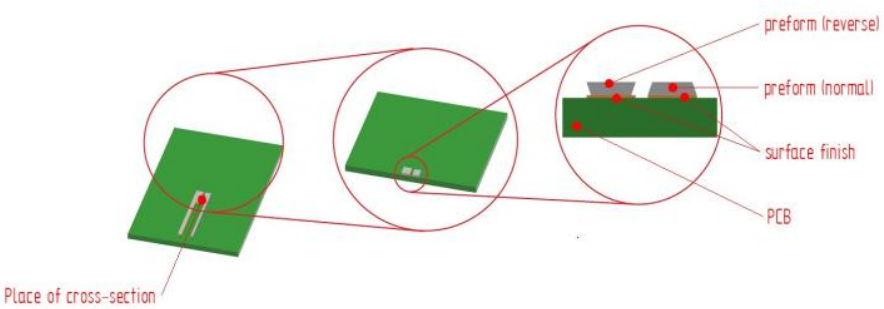

Fig. 7. Schematic draw about the preform placement on the iAg surface finish before soldering. 

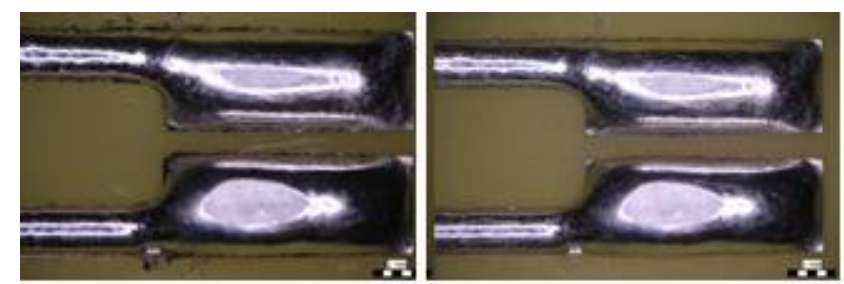

Fig. 8. Two examples for test structure of Sn-Sb solder alloy after hand soldering and before WD test.

\subsection{Platform of WD test}

The ability of electrochemical migration was checked by WD test. Furthermore, the morphology and elemental composition of the dendrites were also investigated using SEM-EDS methods. During the WD test a $15 \mu \mathrm{l}$ drop of $3.5 \mathrm{wt} \% \mathrm{NaCl}$ was placed onto surface of the samples and then $3 \mathrm{VDC}$ was applied. The formation of dendrite growth was optically followed during the WD test, but it can be observed the velocity of dendrite growth and also the time dependence of leakage current. The schematic of the WD test platform can be observed in Figure 9. During the WD tests real-time optical inspection (video record) was carried out and Mean-Time-ToFailure (MTTF) was measured and calculated with the failure criterion of the first significant voltage jump. In case of every sample type 10-10 measurements were done during the WD test.

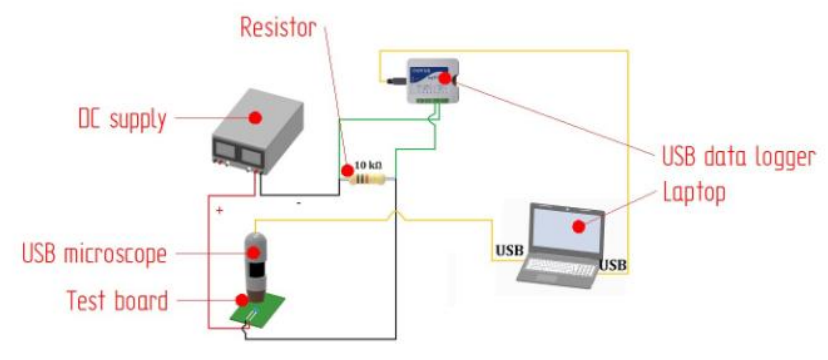

Fig. 9. Schematic draw about the WD test.

\section{RESULTS AND DISCUSSION}

\subsection{Results of the WD test}

Figure 10 presents the MTTF results of the WD test in case of Sn-Sb solder alloys and pure Sn samples. According to the MTTF data, there were no significant differences, only a decreasing trend was observed with the increasing antimony content (See Fig. 10). In order to find out the potential effect of Sb on the ECM behavior, SEM-EDS investigation was introduced.

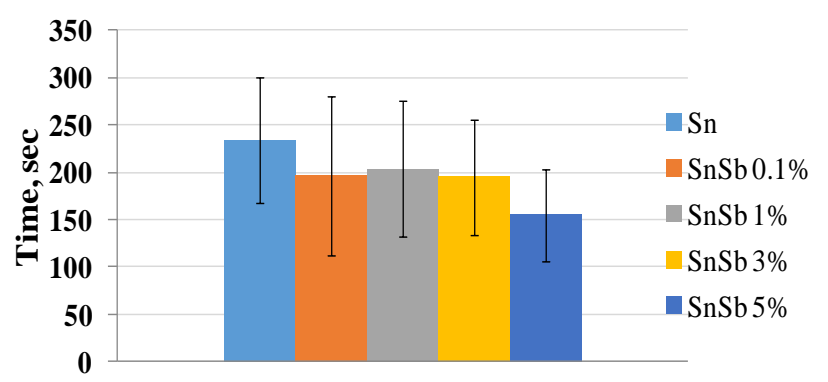

Fig. 10. MTTF data of WD test. 


\subsection{Results of the SEM-EDS investigations}

During the SEM-EDS investigations, rather dendrites were in the focus to get information about their morphology and chemical composition as well. It was found that two types of dendrites were formed: fishbone and tree-like formation. Furthermore, in all cases Sn was dominated the composition of dendrites. However, in case of $\mathrm{Sn}-\mathrm{Sb5 \%}$ a small amount of antimony was detected in the dendrite. Figure 11 presents the SEM picture in case of a Sn-Sb5\% dendrite and the area of the EDS measurement. Table 1 shows the EDS results according to Figure 11.

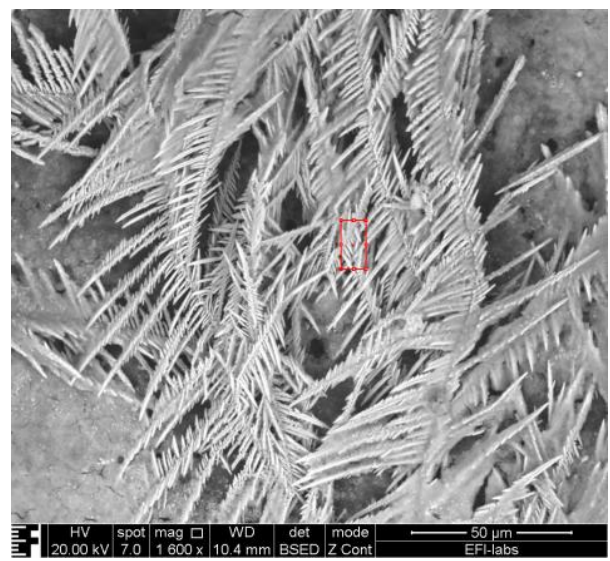

Fig. 11. SEM picture of a dendrite grown form SnSb 5\% solder alloy sample (red rectangle: place of the EDS measurement).

Table 1. EDS results according to Figure 11.

\begin{tabular}{|l|c|c|c|c|c|}
\hline Dendrite & O & Na & Cl & Sn & Sb \\
\hline at\% & 49 & 28 & 9 & 13,5 & 0,5 \\
\hline wt\% & 24 & 19 & 10 & 45 & 2 \\
\hline
\end{tabular}

\section{CONCLUSIONS}

WD test and SEM-EDS methods were applied to investigate the ECM susceptibility of various Sn-Sb alloys and pure Sn surface finish used in electronics. The results show that all of the Sn-Sb solder alloy types have similar ECM risk comparing to the pure Sn. However, an increasing ECM tendency was found with increasing antimony content. Furthermore, in case of Sn95-Sb5 solder alloy antimony was found in the dendrites. It means that $\mathrm{Sb}$ was taken part during the ECM processes in case of Sn95Sb5 solder alloy. Furthermore, the $\mathrm{Sn}-\mathrm{Sb}$ wt \% ratio of the dendrite was similar compare to the original Sn95Sb5 alloy content.

\section{ACKNOWLEDGEMENT}

This paper was supported by the János Bolyai Research Scholarship of the Hungarian Academy of Sciences. The authors would like also thank to the Pro Progressio Fundation (Hungary) for the financial support. 


\section{REFERENCES}

[1] V. Verdingovas, M. S. Jellesen, R Ambat, "Impact of $\mathrm{NaCl}$ Contamination and Climatic Conditions on the Reliability of Printed Circuit Board Assemblies", IEEE Transactions on Device and Materials Reliability, Vol. 14, No. 1, pp. 42$51,2014$.

[2] O Krammer, B Gyarmati, A Szilágyi, R Storcz, L Jakab, B Illés, A Géczy, K Dušek, "Investigating the thixotropic behaviour of Type 4 solder paste during stencil printing", Soldering \& Surface Mount Technology 291) pp. 10-14, 2017.

[3] B. Illés, B. Horváth, "Tin Whisker Growth from Micro-alloyed SAC Solders in Corrosive Climate", Journal of Alloys and Compounds, Vol. 616, pp. 116-121, 2014.

[4] C-A. Tămaș, N. D. Codreanu, M. Pantazică, "Investigations on modern power supplies development based on custom PCB structures", 38th International Spring Seminar on Electronics Technology (ISSE), pp. 436 -439, 2015.

[5] X. Zhong, G. Zhang, Y. Qiu, Z. Chen, W. Zou, X. Guo, "In situ study the dependence of electrochemical migration of tin on chloride", Electrochemistry Communications, Vol. 27, pp. 63-68, 2013.

[6] B. Medgyes, B. Illés, G. Harsányi, "Electrochemical migration behaviour of Cu, Sn, Ag and Sn63/Pb37. ", Journal of Materials Science: Materials in Electronics, Vol. 23, pp. 551-556, 2012.

[7] J-Y. Jung, S-B. Lee, H-Y. Lee, Y-C. Joo, Y-B. Park, "Effect of Ionization Characteristics on electrochemical Migration Lifetimes of $\mathrm{Sn}-3.0 \mathrm{Ag}-0.5 \mathrm{Cu}$ Solder in $\mathrm{NaCl}$ and Na2SO4 Solutions", Journal of Electronic Materials, Vol. 37, No. 8, pp. 1111-1118, 2008.

[8] V. Verdingovas, M.S. Jellesen, R. Ambat, Influence of sodium chloride and weak organic acids (flux residues) on electrochemical migration of tin on surface mount chip components. Corros. Eng. Sci. Technol. Vol. 48, pp. $426,2013$.

[9] X. Zhong, X. Guo, Y. Qiu, Z. Chen, G. Zhang, In situ study the electrochemical migration of tin under unipolar square wave electric field. J. Electrochem. Soc, Vol. 160, pp. D495, 2013.

[10] S.B. Lee, H.Y. Lee, M.S. Jung, Y.B. Park, Y.C. Joo, Effect of the composition of Sn-Pb alloys on the microstructure of filaments and the electrochemical migration characteristics. Met. Mater. Int, Vol. 17, pp. 617, 2011.

[11]L. Hua, C. Yang, "Corrosion behavior, whisker growth, and electrochemical migration of $\mathrm{Sn}-3.0 \mathrm{Ag}-0.5 \mathrm{Cu}$ solder doping with In and $\mathrm{Zn}$ in $\mathrm{NaCl}$ solution", Microelectronics Reliability, 51,pp. 2274, 2011.

[12]X. Zhong, S. Yu, L. Chen, J. Hu, Z. Zhang, "Test methods for electrochemical migration: a review", Journal of Materials Science: Materials in Electronics, Vol. 28, pp. 2279-2289, 2017.

[13] B. I. Noh, J. W. Yoon, W.S. Hong, S.B. Jung, "Evaluation of Electrochemical Migration on Flexible Printed Circuit Boards with Different Surface Finishes", Journal of Electronic Materials, Vol. 38, No. 6, pp. 902-907, 2009.

[14]B. Medgyes, B. Illés, Richárd Berényi and G. Harsányi, "In situ optical inspection of electrochemical migration during THB tests", Journal of Materials Science: Materials in Electronics, Vol. 22, pp. 694-700, 2011.

[15] G. Harsányi, G. Inzelt, "Comparing migratory resistive short formation abilities of conductor systems applied in advanced interconnection system", Microelectronics Reliability, Vol. 41, pp. 229-237, 2001.

[16] X. Zhong, G. Zhang, X. Guo, "The effect of electrolyte layer thickness on electrochemical migration of tin", Corrosion Science, Vol. 96, pp. 1-5, 2015.

[17] O. Devos, C. Gabrielli, L. Beitone, C. Mace, E. Ostermann, H. Perrot, "Growth of electrolytic copper dendrites. II: Oxalic acid medium", Journal of Electroanalytical Chemistry, Vol. 606, pp. 85-94, 2007.

[18]B. Medgyes, L. Gál, D. Szivós, "The effect of $\mathrm{NaCl}$ on water condensation and electrochemical migration", In: IEEE, 20th International Symposium for Design and Technology in Electronic Packaging (SIITME). Bucarest, Romania, pp. 259-262, 2014.

[19] B. Medgyes, B. Horváth, B. Illés, T. Shinohara, A. Tahara, G. Harsányi, O. Krammer, "Microstructure and elemental composition of electrochemically formed dendrites on lead-free micro-alloyed low Ag solder alloys used in electronics", Corrosion Science, Vol. 92, pp. 43-47, 2015. 